\title{
ANÁLISE DO SERVIÇO DE ATENDIMENTO AO FREQÜENTADOR DE UMA ORGANIZAÇÃO VAREJISTA A LUZ DE UM MARCO REFERENCIAL DE ÉTICA NOS NEGÓCIOS
}

ANALYSIS OF A RETAIL ORGANIZATION IN THE SHOPPING CENTER BUSINESS, IN ITS RELATIONSHIP WITH CLIENTS, VIA CUSTOMER SERVICE, BY USING AN BUSINESS ETHICS THEORY

\section{Álvaro MARCONi ferReIRA pires}

Mestre em Administração (PUC-Minas)

Rua Sebastião Fabiano Dias, 210 - 1505 - Belo Horizonte - MG - CEP 30320-690

E-mail: apires@assettech.com.br

\section{ROBERTO PATRUS MUNDIM PENA}

Doutor em Filosofia (Universidad Complutense de Madrid) Rua Fernandes Tourinho, 470 - 909 - Belo Horizonte - MG - CEP 3011 2-000 


\section{RESUMO}

Este artigo apresenta um estudo de caso que aborda a ética empresarial de uma organização varejista, do setor de shopping centers, no relacionamento com os seus freqüentadores (shoppers), via serviço de atendimento a clientes, por meio do construto teórico da Business Ethics, desenvolvido por Lozano (I999). Do ponto de vista metodológico, os dados foram coletados a partir de entrevista com gestores e aplicação de um questionário baseado nos indicadores 2003 ETHOS de responsabilidade social empresarial. Utilizou-se, também, da análise de conteúdo do código de ética, regimento interno, missão empresarial e manual de atendimento ao cliente. Outros dados foram coletados por meio de observação sistemática, levantamento de dados junto ao SAC, pesquisa no PROCON e simulações de demandas de serviço junto ao SAC. Concluímos que a políticas de relacionamento da empresa com os shoppers que recorrem ao Serviço de Atendimento ao Consumidor (SAC) estão revestidas da preocupação do grupo em melhorar a imagem da instituição junto a esse público. A empresa mostrou-se mais atenta à sua responsabilidade civil no sentido de resguardar-se de eventuais problemas de ordem jurídica nas suas relações com o shopper, do que com a afirmação de valores e sua inserção nos processos administrativos do setor da empresa pesquisado.

\section{PALAVRAS-CHAVE}

Ética empresarial; Responsabilidade social empresarial; Serviço de atendimento a clientes; Shopper.

\section{ABSTRACT}

This article exhibits a case study that analyses the managerial ethics of a retail organization, from the shopping centre sector, in its relation with its regular consumer (shoppers), via the Consumer Attendance Service, utilizing the Business Ethics theoretical construct, developed by Lozano (I999). From the methodological point of view, the data were sampled by an interview with managers, and by the application of a questionnaire, based on the 2003 ETHOS indicators of managerial social responsibility. It was utilized, also, the content analysis of the ethics code, of the internal regiment, of the managerial mission and of the consumer assistance manual. Other data were sampled 
through a systematic observation, a survey of data in the CAS, a research in the PROCON - (Bureau of Consumer Protection), and simulations of service demands in the CAS. We concluded that the company relation policies towards its shoppers, which utilize the Consumer Attendance Service (CAS), manifest the concern of the group in improving the institution image with that public. The company was more concerned with its civil responsibility, to protect itself against eventual juridical problems, in its relationships with its shoppers, than with the values statement and with its insertion in the administrative processes of the researched company sector.

\section{KEYWORDS}

Business ethics; Corporate social responsibility; Costumer service; Shopper.

\section{INTRODUÇÃO}

O presente artigo discute e analisa a ética de uma organização varejista, do setor de shopping centers no relacionamento com os seus shoppers, através do serviço de atendimento a clientes, (SAC), à luz do marco referencial do modelo de Business Ethics (BE), proposto por Lozano (I999). Trata-se da aplicação de uma abordagem teórica em um setor de uma organização varejista que permite compreender como o setor se situa, do ponto de vista ético, à luz do modelo.

Segundo Lozano (I999), a BE diz respeito, essencialmente, à possibilidade de ser identificada uma congruência (ARRUDA; NAVRAN, 2002), entre as tradições éticas utilitarista (da ética dos resultados), aretológica (da ética da virtude) e deontológica (da ética de princípios humanistas). No contexto da empresa, interessa conjugar os objetivos corporativos (resultados econômicos) a um ambiente organizacional que tenha o exercício das virtudes éticas como hábitos presentes na cultura da empresa. Essas virtudes devem ser coerentes com os valores que a empresa afirma em seus documentos formais, entre eles, o código de ética.

A empresa estudada é a maior rede de administração de shopping centers do Brasil. A pesquisa foi desenvolvida junto ao SAC de um shopping, em Belo Horizonte, um dos empreendimentos do grupo. A seleção desta empresa deveu-se à estruturação existente na área do SAC e à abertura de seus gestores para uma pesquisa de caráter acadêmico, para fins de uma dissertação de mestrado.

A demarcação teórica utilizada neste artigo contempla o modelo de BE proposto por Lozano (I999). Este modelo incorpora a teoria dos stakeholders, o estudo dos códigos de ética empresariais e da responsabilidade social das organizações e a cultura organizacional. 


\section{FUNDAMENTAÇÃO TEÓRICA}

A presente pesquisa procurou se firmar, principalmente, no marco teórico da BE, proposto por Lozano, na medida em que, seria necessária a identificação de uma proposta conceitual da ética, que fosse direcionada com o foco nos negócios e pudesse ser verificada por meio das práticas empresarias. A construção do alicerce teórico deste artigo se embasa no triplo referencial proposto por Lozano (I999): a perspectiva da chamada Ética de Responsabilidade, a perspectiva da Ética Afirmativa do Princípio da Humanidade, e a perspectiva da chamada Ética Geradora de Moral Convencional. Estas três perspectivas éticas são integradas por este autor em sua formulação do marco ético referencial da BE. A ética de responsabilidade, relacionada diretamente às conseqüências das ações (ética teleológica), abarca a Teoria dos Stakeholders e a Responsabilidade Social das Empresas. A Ética Afirmativa de Humanidade está atenta à dignidade do ser humano reconhecido como interlocutor válido e afirma a tolerância e o respeito nas relações sociais (ética deontológica). A ética geradora de moral convencional, por sua vez, está atenta à dimensão da cultura organizacional e ao desenvolvimento dos indivíduos na obtenção de determinados bens, mediante práticas compartilhadas (ética da virtude).

\subsection{A DIMENSÃO CONSEQÜENCIALISTA DA BE: A ÉTICA DA RESPONSABILIDADE}

A ética da responsabilidade é a primeira das abordagens do modelo de BE proposto por Lozano (I999). As ações empresariais provocam conseqüências para os diversos públicos com os quais a empresa se relaciona (stakeholders). Assim, a empresa deve promover lucros para os acionistas, mas deve estar atenta aos impactos que produz em seus consumidores, trabalhadores, fornecedores, governo e concorrentes.

Os conceitos sobre stakeholders que formaram as bases para a presente pesquisa foram melhor representados por Carrol (I993) e Frederick et al (I988). Carrol (I993), também considerando as relações entre as empresas e a sociedade, conceitua stakeholders como os grupos ou indivíduos com os quais a organização interage ou mantém interdependência, bem como, todo indivíduo ou grupo que possa ser afetado pelas ações, decisões, políticas, práticas e objetivos da organização (CARROL, I993:60).

A abordagem de Frederick et al (1988) será relevante no que toca à distinção, feita por esses autores, entre os stakeholders primários e secundários. Essa diferenciação é feita de acordo com a relação que há entre a empresa e a sociedade. 
Os stakeholders primários representariam as relações diretas necessárias para que a empresa alcance sua finalidade de produzir bens e/ou prestar serviços para a sociedade, trabalhadores, acionistas, clientes, credores, fornecedores, competidores e distribuidores. Os secundários, por sua vez, são os agentes que recebem e vivenciam, de forma indireta, os impactos causados pela missão primária da empresa, tais como: comunidades locais, governos regionais, nacionais e estrangeiros, movimentos sociais, meios de comunicação, grupos de suporte às empresas, bem como o público em geral.

Entende-se, aqui, o consumidor final - shopper - como um stakeholder primário, dado que ele é um agente que participa das relações diretas, para que a empresa alcance sua missão. Afinal, não é possível imaginar a existência de uma empresa varejista sem a presença e a relação com seus clientes-alvo, ou seja, os consumidores finais. Além disso, o consumidor final é um indivíduo com o qual a organização mantém uma interdependência e que tanto afeta a dinâmica de funcionamento dessa organização, quanto é por ela afetado. Um atestado da grande interatividade entre empresa e o consumidor final é a dinâmica que o próprio setor apresenta com o objetivo de sustentar efetivamente sua relação com este stakeholder primário: o funcionamento dos shoppings centers é dirigido, quase que exclusivamente, para atender às demandas de seus consumidores finais.

A pergunta, do ponto de vista da estratégia empresarial, foi formulada por Carroll (I989): "Quem são nossos stakeholders e como queremos que sejam nossas relações com eles?” Essa mesma autora, porém, chama a atenção para o teor reducionista dessa questão. Afinal, não obstante, as considerações a respeito dos stakeholders possam convergir para uma abordagem predominantemente de estratégias empresariais, é indubitável que essas considerações podem, também, convergir para abordagens legitimadoras e éticas. A abordagem do stakeholders é relevante por efetivar o link entre as estratégias empresariais e um compromisso com a ética nos negócios.

A teoria dos stakeholders age mais como um marco de referência para o auxílio à descoberta de quais são as reais obrigações em que se configuram a responsabilidade social das empresas. Lozano (I999) pondera que não se pode considerar a teoria dos stakeholders um construto eticamente auto-suficiente. A análise dos stakeholders parece uma condição necessária para uma ética nas organizações, tanto no que se refere à exigência ética de atender as conseqüências das próprias ações, como no que se refere na construção da responsabilidade. Lozano aponta que é necessário evitar a confusão entre a gestão orientada aos stakeholders e a ética da organização. Assim, considera-se que a ética da responsabilidade precisa ser complementada por outras abordagens éticas. Da síntese dinâmica entre as abordagens éticas, Lozano desenvolveu o seu modelo de Business Ethics. 


\subsection{A DIMENSÃO DEONTOLÓGICA DA BE: O PAPEL DOS CÓDIGOS DE ÉTICA EMPRESARIAIS NA FORMAÇÃO DE UMA ÉTICA DE HUMANIDADE}

A busca por resultados é limitada pela afirmação de valores. Os valores empresariais, em geral, são afirmados em documentos formais, entre eles o código de ética empresarial. De um modo geral, segundo Lozano (i999), a grande maioria dos estudos a respeito dos códigos de ética empresarial privilegiaram aspectos quantitativos, e com características identificáveis muito mais relacionadas à forma do que ao conteúdo, construídos com terminologias próprias.

Preliminarmente, não resta dúvida de que o simples estabelecimento de regras para a organização não significa ser ética a empresa. Mais que isso, tais códigos podem funcionar como instrumento de controle em vez de afirmar uma ética de humanidade. Todavia, podem também perder a perspectiva de autonomia e liberdade e converter-se em uma ferramenta legalista, fechada em si mesma. Enfim, assim como a ética da responsabilidade, a afirmação de uma ética de humanidade é uma dimensão tão necessária como insuficiente para a definição do marco ético referencial para a BE.

As questões mais importantes, a respeito dos códigos de ética, para as quais ainda não se encontraram respostas conclusivas, de acordo com Lozano (I999), seriam as seguintes:

I. Quem tem que participar da formulação do código de ética profissional e por meio de que procedimento esta se dará?

2. De que formas serão conjugadas a expressão dos ideais empresariais e a regulamentação de determinadas práticas organizacionais?

3. Os códigos deverão definir as diretrizes de atividade da empresa ou os princípios gerais regulamentadores da gerência dessa empresa?

4. Serão privilegiadas as funções internas em detrimento das funções externas, ou buscar-se-á o equilíbrio entre ambas?

5. Há uma finalidade meramente enunciativa nesses códigos ou eles irão prever, também, os mecanismos que possibilitarão a efetivação prática desses enunciados?

6. Os códigos irão fomentar a legitimação social e o desenvolvimento da responsabilidade social da empresa?

Entendemos que, mais relevante do que estabelecer uma definição aplicável ao modelo da pesquisa, objeto do presente trabalho, é poder encontrar na construção do marco teórico da ética de humanidade, o que poderíamos denominar de "valores fundamentais" para uma adequada interpretação dos instrumentos 
de auto-regulamentação identificados nas organizações pesquisadas. Tais valores teriam o poder não somente de nortear decisões empresariais, mas de limitar aquelas que os violariam.

A miríade de elementos formais, auto-reguladores, representados em sua grande maioria pelas missões empresariais, crenças, códigos de ética, manuais de procedimentos e posturas, usualmente encontrados nas organizações, demandam, por parte do pesquisador, uma visão interpretativa do sistema, da organização e do indivíduo.

\subsection{A DIMENSÃO ARETOLÓGICA DA BE: A ÉTICA GERADORA DE MORAL CONVENCIONAL}

Conforme explicitado anteriormente, tanto a ética da responsabilidade quanto a ética afirmativa de humanidade são necessárias, mas insuficientes para estabelecer um modelo de ética empresarial. A prática da virtude necessita estar imbricada nos processos formais e informais da organização, isto é, na sua cultura. Sabemos que a cultura é resultado da prática contínua e habitual dos membros que compõem um determinado grupo social. Pensar a cultura de uma empresa é pensar o comportamento dos membros que dele participam.

Consideramos importante que seja feita a distinção entre a ética empresarial (BE) e a cultura organizacional, já que, comumente, "há uma tendência a identificar a ética com a cultura empresarial" (LOZANO, I999:20I). Lozano diz que esse reducionismo leva a uma série de mal-entendidos encontrados, por exemplo:

I. Na tensão existente entre o business ethics e a ethics in business;

2. Na tentação de superar nas empresas e nas organizações os fundamentos pré-convencionais por meio da instauração de uma moral convencional incapaz de alcançar uma perspectiva pós-convencional;

3. E, finalmente, no risco de não se conseguir, jamais, formular uma ética empresarial cujo discurso moral seja verdadeiramente observador do princípio de humanidade.

Gerar uma moral convencional no interior da organização significa fazer com que os valores proclamados sejam efetivamente enraizados nas práticas e processos administrativos. A ética empresarial exige que a cultura organizacional seja a expressão dos valores assumidos e afirmados pela companhia.

Enfim, o modelo de ética empresarial proposto por Lozano busca articular três abordagens éticas. Ao mesmo tempo em que exige a presença de uma ética de responsabilidade, preocupada com as conseqüências das condutas, seus impactos, riscos, inclusive em longo prazo, exige também a presença de uma 
ética de humanidade, preocupada em ser fiel aos valores e critérios éticos que norteiam a conduta, e demanda, também, uma ética geradora de moral convencional, uma ética da virtude, refletida no comportamento e configuradora de sujeitos e contextos empresariais. A partir desse modelo, desenvolvemos a presente metodologia e a aplicamos conforme estudo de caso, a seguir.

\section{METOdOLOGIA}

Do ponto de vista metodológico, a empresa que foi investigada é um Shopping Center, situado no Brasil, na cidade de Belo Horizonte. Com o objetivo de tornar a investigação viável, se tomou como objeto para a análise o serviço de atendimento ao consumidor - SAC - com foco no stakeholder consumidor (mais especificamente o freqüentador shopper). Buscou-se avaliar, por meio dos múltiplos dados coletados, de que forma estaria posicionado o serviço de atendimento a clientes à luz do modelo proposto, bem como responder às questões que compuseram o objeto da pesquisa, a saber:

a) Identificar a perspectiva da ética de responsabilidade: por meio da avaliação da Responsabilidade Social (RS) da empresa em relação ao stakeholder shopper. Para avaliar a RS da empresa em relação ao stakeholder shopper, utilizou-se o instrumento dos indicadores 2003 ETHOS de responsabilidade social empresarial, instrumento reconhecido de avaliação da gestão, planejamento e concretização das estratégias que contribuem para o desenvolvimento social da empresa.

b) Identificar a perspectiva da ética de humanidade: por meio da investigação e de pesquisa nos valores instrumentos formais da organização. A fim de investigar e apresentar os valores afirmados nos instrumentos formais da organização, procedeu-se análise no código de ética, missão empresarial, instrução de serviço, com vista a identificar os valores empresariais que norteiam as relações com o stakeholder shopper.

c) Identificar a perspectiva da ética geradora de moral convencional: por meio da verificação dos dispositivos presentes na estrutura e na cultura organizacional de atendimento ao shopper. Para instrumentalizar os dispositivos presentes na estrutura e na cultura organizacional de atendimento ao shopper, efetivou-se o processo de observação sistêmica, a partir dos contornos percebidos através do mapeamento da cultura interna predominante nas relações com o stakeholder shopper. Serviram para este fim, os documentos formais identificados na pesquisa e os dados adquiridos predominantemente no SAC - serviço de atendimento ao consumidor, desta forma, possibilitando fazer um paralelo entre a vontade empresarial e a prática. 
d)

\section{QUADRO I}

CORRESPONDENCIA ENTRE OS INSTRUMENTOS DE PESQUISA E O MODELO REFERENCIAL DA BE

\section{Modelo referencial da $\mathrm{BE}$ \\ (LOZANO, I999)}

\section{Instrumentos}

de Investigação

\section{Representação} gráfica (a) Ética de responsabilidade (em relação aos freqüentadores do shopping center)
Aplicação do questionário 2003 Indicadores ETHOS de Responsabilidade Social e Empresarial (Gerente de Marketing e Coordenadora do SAC)

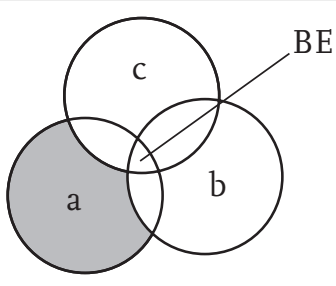

(b) Ética afirmativa de humanidade
Análise do conteúdo do código de ética, do regimento interno, da missão empresarial, manual de atendimento ao cliente.

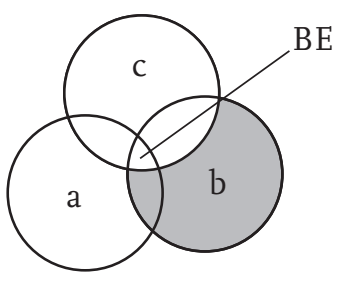

(c) Ética geradora de Observação sistemática, moral convencio- levantamento de dados nal junto ao SAC, pesquisa no PROCON, simulações.

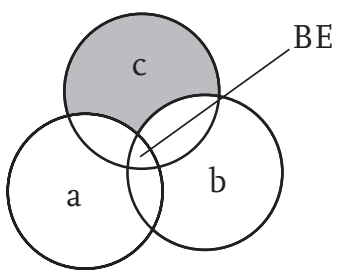

(d) Integração dos três pilares do modelo da BE
Entrevistas, análise da congruência entre os dados coletados.

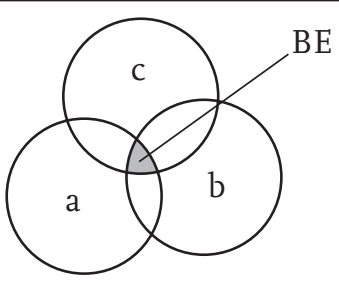

e) Identificar se há congruência ética no setor da organização pesquisado, em conformidade ao modelo proposto por Lozano (1999): por meio da análise e a constatação de uma congruência, a partir da premissa em que, os valores afirmados (b) nos instrumentos formais da organização são praticados (c) na relação com os shoppers insatisfeitos (aqueles que recorreram à organização via SAC - serviço de atendimento ao consumidor, e-mails, correspondências, call-center) conforme a política de responsabilidade da empresa perante seus shoppers (a). 
Os dados foram coletados por meio de entrevistas com os gestores, com a aplicação do questionário 2003 Ethos de Responsabilidade Social e Empresarial, através da análise de conteúdo de documento similar ao código de ética, do regimento interno, da missão empresarial e do manual de atendimento ao shopper. Outros dados foram coletados por meio de observação sistemática, levantamento de dados junto ao SAC (dados de dezembro de 2002 a maio de 2003), pesquisa junto ao PROCON e simulações de demanda de serviço junto ao SAC. Os instrumentos metodológicos podem ser resumidos de acordo com o quadro I.

\section{ANÁlise dos dados}

Procuramos analisar os dados por meio de uma abordagem que pudesse ser interpretada dentro dos vértices conceituais que fundamentaram nossa pesquisa, pontuados pela ética de responsabilidade, a ética afirmativa de humanidade, a ética geradora de moral convencional e a congruência das éticas na formação de uma BE, a partir dos instrumentos de investigação apontados na metodologia.

\section{1 ÉTICA DA RESPONSABILIDADE}

Questionário dos indicadores 2003 ETHOS de responsabilidade social empresarial

Procuramos, neste tópico, analisar os dados por meio do vértice conceitual da ética de responsabilidade. Com o objetivo de analisar a atenção dada pela empresa às suas ações de responsabilidade social, outro marco importante destacado por Lozano (I999) dentro do vértice da ética de responsabilidade, utilizamos os indicadores 2003 Ethos de responsabilidade empresarial e social para investigar esse quesito. Procuramos verificar quais seriam as ações da empresa, voltadas para o stakeholder shopper, que pudessem ser apontadas para uma atenção de RS com esse agente. Utilizamos as respostas dos tópicos 23, 24 e 25 do questionário 2003 Ethos, dadas pela supervisora do SAC e pela gerente de marketing do SC, com o objetivo de construir um quadro de referência sobre a presença de uma ética de responsabilidade junto ao consumidor do shopping.

Um dado significativo diz respeito às discrepâncias verificadas entre as respostas da coordenadora do SAC e as da gerente de marketing. Quando houve discrepância entre as respostas, as mais positivas ou favoráveis à empresa foram sempre da gerente de marketing da empresa. Cabe ressaltar que, de acordo com Moura, Ferreira e Paine (I998:86) existe a possibilidade de haver um viés nas respostas dos gestores entrevistados. Entendemos ser prudente apontar a possibilidade da existência de um cunho mercadológico nas respostas, principalmente 
pelo fato de serem os entrevistados profissionais contratados para gerir as ações de marketing da organização em seu nível operacional. Como exemplo de uma discrepância, podemos citar uma questão em que se pergunta se nos últimos três anos ocorreram denúncias aos órgãos de defesa do shopper. A supervisora do SAC afirmou que sim. Já a gerente de marketing disse que não. Verificamos com o PROCON que as denúncias, quando resolvidas, não figuram no banco de dados da entidade, dessa forma, tornou-se inviável apurar a resposta correta. Em outra questão, indagou-se como está a organização quanto ao conhecimento e gerenciamento dos danos potenciais de seus produtos e serviços. A supervisora do SAC enquadrou a empresa no estágio 3. A gerente de marketing avaliou o grau de conhecimento organizacional no estágio 4. Configura-se aqui uma importante hipótese a ser verificada em outras pesquisas: quanto menor o nível hierárquico de quem responde a questionários ou entrevistas relativas à responsabilidade social da empresa, maior a tendência de resposta desfavoráveis à empresa.

Com relação ao stakeholder shopper, podemos verificar que, apesar das discrepâncias mencionadas, a empresa demonstra ser responsável, o que pode ser verificado pelo grau de comprometimento verificado nas respostas ao questionário 2003 Ethos. A maioria das respostas situaram a empresa dentro de elevados níveis de preocupação com o shopper, conforme resultado apresentado nas respostas do questionário, situando, na maioria das vezes, entre os níveis 3 e 4 . Veremos que esse dado não se mostrou congruente com as outras duas perspectivas pesquisadas. Configura-se aqui outra hipótese relevante para futuras pesquisas: a entrevista parece um instrumento insuficiente para a verificação de uma ética empresarial.

\section{2 ÉTICA AFIRMATIVA DE HUMANIDADE}

Procurou-se, neste tópico, analisar os instrumentos gerenciais da empresa mediante a consideração dos processos de auto-regulação com os quais a organização elabora e constrói reflexivamente seus valores, suas finalidades e seus critérios de atuação, para com os seus shoppers, em conformidade com o marco teórico proposto por Lozano (I999), da ética afirmativa de humanidade. Concentramos nossa análise nos documentos formais - código de ética (denominado de Princípios Empresariais), missão empresarial, regimento interno e instrução de serviço.

\section{Código de ética}

Identificamos como código de ética da empresa o documento denominado Princípios Empresariais. De acordo com o depoimento da superintendente geral 
de marketing da empresa, esse documento deve ser transformado em um código de ética empresarial. O documento em questão trata das posturas, valores e crenças e é divulgado de forma ampla na organização e em sua página na internet. O instrumento se subdivide nas seções relacionadas aos stakeholders fornecedores, aos que são denominados de stakeholders parceiros, aos stakeholders colaboradores e, por fim, às ações de responsabilidade social.

De acordo com Brooks (1989), existem três modelos de códigos de ética empresarial: os que têm como referência os stakeholders, outros que se referenciam na política estratégica e, finalmente, aqueles cuja referência é a missão empresarial. O instrumento apresentado que reflete as aspirações éticas da empresa se assemelha ao primeiro tipo, o que tem como referência principal os stakeholders, porém inclui em seu bojo uma referência à sua política estratégica quando aponta as iniciativas no campo da responsabilidade social.

No instrumento citado acima, não são mencionados quais são os princípios gerais da empresa em relação ao stakeholder shopper. Observamos uma preocupação voltada para estruturar o relacionamento da empresa com os stakeholders fornecedores, stakeholders empregados e stakeholders parceiros. Ao analisar o instrumento, verificamos a presença de propósitos que representam o conjunto de princípios gerais da companhia e que são obrigatórios (códigos de responsabilidade profissional). Referimo-nos às normas de comportamento, que se manifestam basicamente com relação aos fornecedores. Das seis normas descritas, quatro são negativas (dizem o que não deve ser feito), ao passo que duas são positivas (dizem o que deve ser feito). As negativas dizem respeito à proibição de contratação de empresas ou consultorias pertencentes a colaboradores desligados da empresa há menos de cinco anos, como também de contratar empresas que mantenham quaisquer relações de parentesco com os funcionários, de aceitar gratificações ou prêmios de fornecedores e de falar sobre projetos passados, em realização ou a serem realizados para o grupo $\mathrm{Y}$ ou quaisquer umas de suas empresas.

Como descrito na revisão feita por Lozano (I999), fala-se somente na proibição de receber propina, mas omite-se a de dar presentes e subornos. Do mesmo modo, a empresa veta a contratação de empresas de ex-funcionários e de familiares de funcionários, mas não menciona a proibição da contratação de empresas de funcionários. Como se pode perceber, esse é um dos problemas advindos de um texto normativo negativo. Por isso, o código de ética não deve ser concebido como um instrumento suficiente para o estabelecimento de uma ética empresarial. O risco apontado por Lozano (I999) se faz aqui presente: o que não estiver explicitado no Código de Ética pode ser considerado como permitido.

A omissão do stakeholder shopper no escopo do instrumento intitulado Princípios Empresariais motivou-nos a questionar quais seriam os motivos de esse constituinte tão importante haver sido negligenciado. A administração de um shopping 
não lida com o consumidor, mas justamente com o freqüentador (shopper). Ainda que possa ser considerado um agente indireto nas relações empresariais, mediado pelos lojistas e prestadores de serviços de cada shopping center, o Serviço de Atendimento ao Cliente (SAC) atende não ao consumidor das lojas, mas justamente ao shopper, não justificando a sua omissão nos documentos formais da empresa. Negligenciá-lo parece um contrasenso para uma empresa varejista de administração de shoppings, que posiciona o seu negócio em ofertar a melhor prestação de serviços ao seu shopper.

Assim sendo, verificou-se que a preocupação da empresa pesquisada, no tocante ao instrumento que relaciona os princípios empresarias, negligencia a sua relação com o seu stakeholder shopper, embora se possa inferir que os valores explicitados na relação com os fornecedores devam ser estendidos à relação com o shopper. Os valores explicitados no código de ética foram os seguintes: sucesso nos negócios, honestidade, transparência, integridade, lealdade, confiança, reciprocidade, excelência nos serviços, respeito ao ser humano, competência técnica e superação contínua. Não identificamos valores implícitos.

\section{Regimento interno}

O regimento interno procura estabelecer as formas de uso do shopping, o que não o distancia muito de uma convenção de condomínio de um prédio de apartamentos. Entendemos que o regimento interno, ao longo de seus noventa e quatro artigos, apresenta em seu conteúdo um conjunto de preceitos normativos que objetiva garantir operacionalidade ao negócio, sem, contudo, expressar a afirmação do princípio de humanidade. O instrumento concentra-se no foco normativo e negligencia o foco reflexivo. Em grande parte dos artigos, as disposições são proibitivas, sugerindo o caráter pré-convencional do documento, que procura assegurar a eficácia dos negócios.

O stakeholder shopper é caracterizado como clientes ou fregueses, e é descrito como "compradores de qualquer das lojas e os usuários dos serviços existentes oferecidos nas instalações do SC" (Art 5ำ, letra j). O usuário apontado na definição de consumidor é definido pelo Regimento como "qualquer pessoa física ou jurídica, que se utilizar em caráter transitório ou permanente, de qualquer área, dependência ou serviço do shopping, mesmo que em simples trânsito".

Observamos que, na redação do regimento interno, a definição do stakeholder shopper final pode suscitar interpretações dúbias quanto à identidade desse constituinte. Um funcionário ou um locatário, quando utiliza as dependências do SC, pode se considerar um usuário, mesmo estando a serviço ou em sua atividade profissional. Ou seja, devemos considerar no regimento a citação de usuário como a caracterização do shopper para todas as pessoas que circulem pelo shopping. 
Os valores que norteiam a relação do shopping com seus shoppers ou usuários dizem respeito a normas mínimas de segurança, limpeza e funcionamento do estabelecimento. Ou seja, o regimento interno sugere maior preocupação da empresa em estabelecer normas regulatórias que possam assegurar o bom andamento das atividades empresariais e apontar direitos e obrigações - mais obrigações do que direitos - dos lojistas em relação ao empreendimento. A referência ao shopper é, mais uma vez, incidental. Por exemplo, no artigo 9०, quando se exige o zelo dos lojistas para que seus empregados tenham boa apresentação pessoal e trajes convenientes para atendimento aos shoppers.

\section{Missão empresarial}

A empresa não dispunha, à época da coleta de dados, de um enunciado caracterizado como missão empresarial.

\section{Manual de Atendimento ao Cliente}

O Manual de Atendimento ao Cliente é o instrumento que operacionaliza e instrui como os procedimentos e as condutas devem ser praticadas pela administração do shopping, quando o shopper recorre aos serviços do SAC. Trata-se de uma coletânea de informações e recomendações que devem ser seguidas pelos profissionais da área do SAC.

O tratamento dado ao shopper no Manual de Atendimento ao Cliente sugere que o shopper é um meio para a obtenção do sucesso empresarial e não um fim em si mesmo. Contrariamente à abordagem conceitual de Donaldson e Preston (I995), que propõem uma justificativa ética para a administração dos stakeholders, na medida em que tais agentes têm valor intrínseco, devendo ser considerados a partir de si mesmos e não como um veículo para atender aos interesses de outros agentes, em especial dos acionistas, o documento analisado nos pareceu considerar o shopper à medida que influencia os resultados empresariais. Tratase, portanto, de uma abordagem instrumental, que vê o shopper como meio para a realização dos interesses empresariais. As atividades do SAC parecem, a partir do instrumento analisado, um meio de obtenção de sucesso junto ao shopper e não como um fim em si.

\section{3 ÉTICA GERADORA DE MORAL CONVENCIONAL}

Os instrumentos metodológicos utilizados para verificar a existência de uma ética geradora de moral convencional buscaram descrever os comportamentos habituais no interior do Serviço de Atendimento ao Cliente - SAC. 


\section{Observação sistemática}

Ao analisar o treinamento para o atendente do SAC, buscou-se o Manual de Atendimento ao Consumidor para comparar a prática com o discurso. Reconhecemos no texto a relevância que é dada pela empresa ao assunto. A partir da verificação da importância formal que a empresa dá ao processo de treinamento, conforme o manual de atendimento, analisamos o texto "como fazer um excelente treinamento" e buscamos relacioná-lo com as políticas de treinamento da empresa. De fato, os quinze passos relacionados no documento foram desenvolvidos com vistas a capacitar o atendente no processo de atendimento ao shopper. Trata-se, portanto, de um processo normativo, que procura orientar o atendente em posturas, fraseologia e atitudes que possam conduzi-lo a um melhor serviço prestado. Observou-se, nas visitas ao SAC, uma discrepância entre os propósitos empresariais sobre o perfil do atendente do SAC e os profissionais selecionados para a função. Todos são estagiários, com contratos temporários o que, via de regra, diminui a perspectiva de ser uma função encarada como de grande responsabilidade e importância pelos gestores da organização.

O manual descreve no tópico (e), "perfil do atendente do SAC", as habilidades, valores e conhecimentos necessários ao exercício da função. Considera que o atendente deve ser uma pessoa com capacidade de se identificar com os clientes, entender suas necessidades e tentar solucionar seus anseios, [bem como,] a função é, portanto, de grande responsabilidade e importância, pois o objetivo de cada atendimento é a satisfação do cliente e a melhora dos serviços prestados. (Manual do Atendente do SAC). Este ideal pareceu longe do que foi observado na pesquisa.

\section{Levantamento de dados junto à área de SAC}

Passou-se, a seguir, à análise da estatística do serviço de atendimento ao cliente, com os dados levantados no período compreendido entre dezembro de 2002 a maio de 2003. Mediante uma customização de informações, geradas pelo banco de dados, Data Base DB 2000, foram levantados os mais relevantes dados a respeito do relacionamento e prestação de serviços do SAC SC para com o seu shopper. As insatisfações apresentadas pelos shoppers via SAC foram classificadas de acordo com a sua natureza - atendimento, devolução de mercadorias, informações contraditórias e equivocadas, preços e pagamentos, qualidade dos serviços, acesso ao local, segurança. $\mathrm{Na}$ análise dos dados que registram as insatisfações dos shoppers, foi verificado como a empresa atuou no sentido de dar solução e respostas aos questionamentos apresentados. O presente instrumento, em si, constitui-se em um quadro temporal do que levou o shopper a procurar o SAC. 
As ações que se seguem, a partir da interpretação da estatística de atendimento ao shopper, sugerem um vínculo com o vértice da ética de responsabilidade, no ponto em que as informações disponibilizadas auxiliam a empresa a minimizar os possíveis atritos e insatisfações na relação com o seu shopper. O confronto da estatística analisada com a perspectiva da ética de humanidade, permitiu inferir que tais dados podem auxiliar a empresa na construção de valores que atuem positivamente nas relações da empresa com o seu shopper. Entretanto, não se verificou o uso deste recurso potencial.

\section{Pesquisa no PROCON}

Efetuou-se consulta formal ao PROCON sobre possíveis denúncias de shoppers ao SC. Obteve-se resposta que nada constava nos arquivos daquela autarquia que pudesse desabonar a empresa pesquisada, configurando, por meio de um instrumento formal emitido por terceiros, um provável sinalizador das posturas empresariais frente às responsabilidades em relação aos seus shoppers. Entretanto, este dado contrastava com a resposta dada pela coordenadora de atendimento do SAC sobre a ocorrência de denúncias aos órgãos de defesa do consumidor. Verificou-se que as queixas solucionadas não figuram no cadastro de informações do PROCON.

\section{Simulações}

Foram realizadas duas consultas ao SAC para verificar o serviço, uma por e-mail e outra pelo telefone 0800 . Simulou-se uma queixa (embora real) relativa à cobrança do estacionamento, implementada recentemente. A queixa feita via e-mail não foi respondida. Quanto ao telefonema, o atendimento se deu prontamente e a queixa foi ouvida pela atendente. Um mês depois, tentou-se fazer uma nova queixa pelo telefone 0800 , mas uma gravação da operadora informou que "o número discado não corresponde a um número de serviço ativo". Ligando para o Auxilio à Lista Io2, solicitamos o telefone do Serviço de Atendimento ao Cliente do shopping. O telefone informado foi o geral. Por meio desse número, a telefonista encaminhou a ligação para o SAC, quando foi feita a reclamação (também real) de uso de fumo de cigarro na área de alimentação do shopping, onde existem placas indicando a proibição. Entretanto, a atendente respondeu que a pessoa responsável por registrar a queixa não estava no momento. Ela solicitou o telefone de contato e prometeu retornar a ligação em cinco minutos. O número do telefone de contato fornecido foi o de um telefone celular. Não houve retorno do SAC. 


\subsection{INTEGRAÇÃO DOS TRÊS PILARES}

Entrevistas foram realizadas com a coordenadora do SAC e a gerente de marketing do shopping. As entrevistas foram elaboradas por meio de um roteiro de perguntas que procuravam remeter o entrevistado à qualidade dos serviços prestados pelo SAC. Ambos os entrevistados procuraram demonstrar que existe uma preocupação no aprimoramento dos serviços prestados aos shoppers que recorrem ao SAC. A coordenadora do SAC mostrou-se mais detalhista ao avaliar os recursos, a qualidade e a dinâmica gerencial de atendimento ao shopper. Apontou limitações inerentes à sua área que dificultam um melhor atendimento ao shopper, relacionado à impossibilidade de interferência na operação dos lojistas. A gerente de marketing apontou os serviços prestados pelo SAC como de ponta. Entretanto, quando argüida sobre a avaliação do shopper, a resposta, apesar de não ser contraditória, sugere que o shopper não atribuiria aos serviços do SAC uma graduação de excelência.

Questionados a classificar, em termos percentuais, os macro objetivos da organização no tocante ao relacionamento com o shopper, os entrevistados, ao distribuírem a totalidade percentual, informaram um valor relativamente baixo para o objetivo de interação entre o colaborador e o shopper. Os maiores objetivos empresariais foram direcionados para a otimização de resultados e a imagem da empresa. Ao analisar como foram respondidas as questões relacionadas aos propósitos e trabalhos desenvolvidos pelo SAC do shopping, constatou-se, novamente, a possibilidade destacada por Moura, Ferreira e Paine (I998:86), de que os questionários podem ser afetados pela desejabilidade social, isto é, "a possibilidade das pessoas darem respostas que não correspondam efetivamente à sua opinião, e sim respostas que estão de acordo com as convenções e normas sociais".

Quanto à possibilidade de congruência proveniente da análise das entrevistas feita com os gestores e de nossa observação, à luz do modelo de Lozano (I999), conclui-se que o shopper é visto, pelos gestores entrevistados, como um constituinte que interfere de forma direta nos objetivos empresariais e, assim sendo, merecem atenção e empenho no sentido de uma oferta melhor na prestação dos serviços. Observou-se que a empresa, o seu ambiente interno e seus empregados têm uma orientação e uma postura profissional voltadas para o mercado varejista de prestação de serviços aos shoppers finais. Dessa forma, naturalmente foram incorporadas muitas das técnicas de relacionamento e marketing para construir o processo de interação com seus shoppers. Não se percebeu, na análise das entrevistas, o foco para a formação de líderes de um processo de aprendizagem organizacional, conforme orientação de Lozano (I999) para a construção de uma organização que aprende. 
Verificou-se a existência de uma cultura fragmentada, entre as áreas da empresa e mesmo entre os níveis hierárquicos. Trata-se, pois, de um fator que limita a formação de uma cultura organizacional que seja a expressão dos valores convencionais.

\section{CONCLUSÕes}

Este trabalho teve por objetivo entender como se processa a relação de uma empresa varejista de prestação de serviços em administração de shopping centers com os seus shoppers. O modelo de análise foi o marco ético referencial da BE, proposto por Lozano (I999). Avaliou-se a ética da responsabilidade da empresa em relação ao stakeholder shopper, investigou-se a ética afirmativa de valores de humanidade nos documentos formais da organização e verificaram-se os dispositivos presentes na estrutura e na cultura organizacional de atendimento ao shopper. A partir do levantamento desses dados, conferiu-se se os valores afirmados pela organização são praticados na relação com os shoppers insatisfeitos (aqueles que recorreram à organização via SAC, e-mails, correspondências, call-center), conforme a política de responsabilidade da empresa perante seus shoppers. Procurou-se pesquisar quais seriam os valores que norteiam as ações de relacionamento com o shopper e se tais valores apresentavam uma congruência com o modelo da BE. O SAC foi a área da empresa que investigada, para o levantamento dos dados.

A interpretação dos valores empresariais, com base no marco da BE, trouxe para esta pesquisa vantagens analíticas e conceituais se comparadas a outras tradicionais formas de abordagens do tema da ética nas organizações. Em primeiro lugar, porque os fundamentos do marco teórico da BE podem ser confrontados, a partir do levantamento de dados existentes na empresa e, daí, analisados à luz de um molde que minimiza a abstração. Em segundo lugar, porque apresenta ao pesquisador a oportunidade de formular as questões investigativas por meio de um método, permeado pelo conteúdo teórico e eficaz no reconhecimento da BE na organização pesquisada. Em terceiro lugar, por oferecer uma nova perspectiva do desenvolvimento de estudos relacionados à ética e ao marketing nas organizações.

O levantamento dos dados foi desenvolvido, observando-se a metodologia recomendada para um trabalho de pesquisa relacionado a um estudo de caso. A partir da análise dos dados, chegou-se à conclusão de que as políticas e as ações de relacionamento da empresa com os shoppers, que recorreram ao SAC, estão revestidas da preocupação do grupo em zelar pela imagem da instituição junto a esse público, o que, denota uma preocupação estratégica (instrumental) da empresa com a sua reputação. 
A partir da premissa, evidenciada por Lozano (I999), de que o conhecimento analítico dos stakeholders é um caminho para a construção de uma ética nas organizações, verificou-se que a empresa não caminha na busca desse conhecimento, embora reconheça, nas práticas de atendimento ao shopper, um meio privilegiado de coleta de informações. A partir da abordagem de Donaldson e Preston (I995), aponta-se o caráter instrumental do SAC, sendo o o shopper considerado não por seus valores intrínsecos e sim, a partir da significância que esse agente tem como veículo para atender aos interesses de outros agentes, em especial dos acionistas.

Quanto aos valores afirmados nos documentos formais da organização, verificou-se que os processos de auto-regulação com os quais a organização elabora e constrói seus valores, suas finalidades e seus critérios de atuação revestem-se muito mais de uma moral pré-convencional, com a predominância de aspectos normativos e proposições negativas (proibições).

Não se constatou, na extensão da pesquisa, o foco estratégico da empresa em se posicionar como uma promotora de processos que ensejem o aprimoramento da cultura empresarial no contexto da BE, principalmente nos termos de Gagliardi (I986), ao referir-se à criação de cultura como um processo dinâmico de aprendizagem. Provavelmente, esse deva ser o ponto mais fraco identificado na pesquisa.

Observou-se, nas políticas de gerenciamento do SAC, uma excessiva preocupação com os custos operacionais, que se reflete na contratação de estagiários para exercerem as atividades de relacionamento com o shopper e no cancelamento do serviço de atendimento pelo telefone 0800 . O atendente, principal elo entre a empresa e o shopper, apesar de receber treinamento introdutório e periódico, dificilmente incorpora um elevado grau de comprometimento com objetivos estratégicos da área, quando contratado como estagiário. O desejável seria que a empresa estudasse a viabilidade de alocar funcionários devidamente treinados e envolvidos com os planos empresariais e visão de médio e longo prazos. O foco mais evidente na área do SAC dirige-se para a preservação da imagem institucional da empresa junto aos seus shoppers, o que ratifica a observação quanto aos apelos mercadológicos que dão o tom às ações da empresa, mais diretamente do SAC. A partir da análise dos dados, chegou-se à conclusão de que as políticas e as ações de relacionamento da empresa com os shoppers que recorreram ao SAC estão revestidas da preocupação da instituição por sua reputação, o que denota uma preocupação de caráter instrumental, presente nas normas e delimitações formais e também associada aos seus objetivos de marketing de relacionamento.

Percebeu-se a necessidade de aprimorar as práticas administrativas que resultem em melhorar a relação entre e empresa e seus shoppers que demandaram atendimento, por meio de uma política estruturada de seleção e treinamento 
para todos os funcionários que interagem com o shopper, em especial os profissionais do SAC.

Quanto à interpretação dos valores empresariais, com base no marco da responsabilidade, verificamos que a utilização do questionário Ethos de responsabilidade social e empresarial tem a limitação natural de um instrumento qualitativo de pesquisa, principalmente pelo caráter genérico das respostas - que atenda o maior número de empresas participantes do projeto - e pela possibilidade de um viés das respostas que seja do interesse dos entrevistados.

Quanto à interpretação dos valores empresariais, com base no marco de humanidade, podemos concluir pela existência de uma pontual fragilidade da empresa na relação com o seu stakeholder shopper. A inexistência de uma missão empresarial, a omissão do shopper nos Princípios Empresariais - entendido pela organização como o seu atual código de ética - e o tratamento do shopper no Manual de Atendimento ao Cliente, sugerem que, na visão da empresa, o shopper é um meio para a obtenção do sucesso empresarial e não um fim em si mesmo.

Quanto à interpretação dos valores empresariais, com base no marco da ética geradora de moral convencional, verificou-se que a empresa dispõe de recursos adequados para mapear as demandas geradas pelos shoppers junto ao SAC. O banco de dados é bem estruturado, o que permite o levantamento de informações estatísticas que possam dar subsídio ao processo da tomada de decisões. Entretanto, o problema verificado, que também fragiliza a relação da empresa com o seu stakeholder shopper, concentra-se na qualidade e no grau de comprometimento dos atendentes do SAC. Nas simulações efetuadas junto ao SAC, verificou-se um descompasso entre a proposta de atendimento ao shopper, formalizada nos instrumentos e manuais divulgados pela empresa, e o processo efetivo do atendimento. O pesquisador que compara os objetivos e a prática sente-se frustrado em suas expectativas, no que diz respeito à qualidade do atendimento do SAC. A possibilidade de o shopper ter a mesma impressão é significativa e deve ser objeto de atenção da empresa. Outros aspectos que denotam a fragilidade da empresa quanto aos valores empresariais, com base na ética geradora de moral convencional, conforme explicitados na análise das entrevistas, aponta para uma cultura organizacional sem unidade e para a inexistência de uma política interna com foco para a formação de líderes de um processo de aprendizagem organizacional.

Representamos por meio da figura I, o que poderia sintetizar o modelo de análise: 


\section{FIGURA I}

INTEGRAÇÃO DO MARCO ÉTICO REFERENCIAL DA BE, (A,B,C), SEGUNDO MODELO PROPOSTO POR LOZANO (I999)

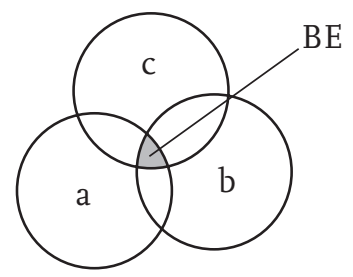

$\mathrm{Na}$ figura 2, apresentamos a síntese dos resultados verificados, a partir do modelo de análise. Os fundamentos da ética de responsabilidade em relação ao seu stakeholder shopper apresentaram um razoável grau de simetria se comparado ao molde conceitual apresentado por Lozano (I999). Os fundamentos da ética de humanidade presentes na empresa, em relação ao seu stakeholder shopper, por sua vez, apresentaram um baixo grau de simetria, quando confrontado ao molde conceitual proposto por Lozano (I999), motivado principalmente pela prevalência dos aspectos pré-convencionais, normativos e de auto-regulação dos valores empresariais em contraste a um posicionamento reflexivo-normativo, arejado, propenso a disseminar a evolução da ética humanista na empresa. Os fundamentos da ética geradora de moral convencional, por fim, presentes na empresa, em relação ao seu stakeholder shopper, não apresentaram simetria em relação ao molde conceitual apresentado por Lozano (I999), dada a pouca evidência, percebida na pesquisa, do desenvolvimento de uma cultura ética da virtude enraizada na cultura da empresa.

\section{FIgURA 2}

INTEGRAÇÃO DO MARCO ÉTICO REFERENCIAL DA BE, (A,B,C), SEGUNDO MODELO PROPOSTO POR LOZANO (I999), NA EMPRESA PESQUISADA

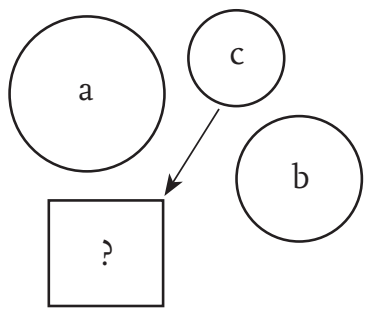


Como resultante, pode dizer-se que inexiste, de forma pontual e consolidada, a integração entre os três vértices de constituição de um processo de Business Ethics (BE) na empresa pesquisada. Há apenas uma preocupação estratégica, pouco eficiente, contida na ética da responsabilidade, com caráter instrumental, de respeito à legislação, que caminha em consonância aos avanços dos direitos dos consumidores - shoppers - e de não ser vítima de problemas jurídicos e de imagem. A perspectiva do atendimento ao shopper demonstra um caráter instrumental, que denota a preocupação com as conseqüências jurídicas e relacionadas à imagem da empresa, o que, em última análise, é insuficiente para a constituição de uma empresa ética, de acordo com o modelo de referência.

Como limitação a ser ponderada na presente pesquisa, destacam-se as próprias de um estudo de caso, que faz uma análise pontual de um momento da empresa. Sua contribuição, por outro lado, está na originalidade em operacionalizar uma avaliação da ética em uma empresa, a partir de um modelo exclusivamente teórico, como o de Lozano (I999). Apresentou-se o shopper como um importante stakeholder para as administradoras de shopping centers. Recomenda-se o desenvolvimento de outras pesquisas semelhantes, que podem valer-se da mesma metodologia aqui apresentada para avaliar outros stakeholders, como exemplo, os fornecedores, os colaboradores e a comunidade.

\section{REFERÊNCIAS}

ARRUDA, Maria C. C. ; NAVRAN, F. Indicadores de clima ético nas empresas. Revista de administração de empresas. v. 40, n.3, p. 26-35, jul/set., 2000.

ASHLEY, P. A. Coordenação. Ética e responsabilidade social nos negócios. São Paulo: Saraiva, 2002. BROOKS, L. J. Corporate codes of ethics. Journal Business Ethics, v. 8, n. I, p. 31-8, I989a.

Corporate codes of ethics. Journal Business Ethics, v. 8, n. 2-3, p. II7-I29, I989b.

CAMPOS, T. L. C. Administração de stakeholders: uma questão de ética ou estratégia. In: ANPAD, Rio de Janeiro. Anais... Rio de Janeiro, 2002.

CARROL, A. B. Ethics and stakeholder management. Business and society. Cincinnati: South-Western Publishing, I989.

A three-dimensional conceptual model of corporate performance. Academy of Management Review, v. 4, n. 4, p. 497-505, I993.

DONALDSON, R.; PRESTON, L. The stakeholder theory of the corporation: concepts, evidence and implications. Academy of Management Review, Missisipi State, v. 20, p. 65-9I.

FREDERICK, W. C.; DAVIS, K; POST, J.E. Business and society corporate strategy, public policy, ethics. New York: MacGraw Hill, I988.

FREEMAN, R. E. Strategic management. A stakeholder approach. Boston: Pitman, I984. Strategic management. A stakeholder theory of modern corporation. In: HARTMAN, Laura

P. Perspectives in business ethics. New York: MacGraw-Hill International Editions, I998. Divergent stakeholder theory. The Academy of Management Review, Apr, I999. 
FREEMAN, R. E. e REED, D. Stakeholders and stakeholders. A new perspective on corporate governance. California Management Review, v. 25, n. 3, p. 88-106, I983.

GAGLIARDI, P. Exploring the aesthetic side of organization life. In: CLEGG, S. R.; HARDY, C., NORD, W. R. Handbook of organization studies. London: Sage, I986.

INDICADORES ETHOS DE RESPONSABILIDADE SOCIAL EMPRESARIAL (2003). Versão 2003, Instituto Ethos de responsabilidade Social Empresarial: São Paulo, Jun. 2003. <www.ethos. org.br>

LOZANO, J. M. Ética y empresa. Madrid: Editorial Trotta, I999.

MOURA, M. L. S.; FERREIRA, M.C.; PAINE, P. A.. Manual de elaboração de projetos de pesquisa. Rio e Janeiro: EDUERJ, I998. I32 p.

SROUR, R. Ética empresarial. Rio de Janeiro: Campus, 2000. 286 p.

WEBER, Max. A ética protestante e o espírito do capitalismo. São Paulo: Pioneira, I997.

\section{TRAMITAÇÃO}

Submissão: 04/08/2004

Aprovação: 05/08/2005 
Copyright of Revista de Administração Mackenzie is the property of Universidade Presbiteriana Mackenzie, RAM-Revista de Administracao Mackenzie and its content may not be copied or emailed to multiple sites or posted to a listserv without the copyright holder's express written permission. However, users may print, download, or email articles for individual use. 